\title{
A Complex Network Approach for Quantitative Characterization and Robustness Analysis of Sandstone Pore Network Structure
}

\author{
Yuhao Hu, ${ }^{1,2}$ Guannan Liu $\mathbb{D}^{1,2,3}$ Feng Gao, ${ }^{2,3}$ Fengtian Yue, ${ }^{2,3}$ and Tao Gao ${ }^{2,3}$ \\ ${ }^{1}$ Jiangsu Key Laboratory of Coal-Based Greenhouse Gas Control and Utilization, Mechanics and Civil Engineering Institute, \\ China University of Mining and Technology, Xuzhou, Jiangsu 221116, China \\ ${ }^{2}$ State Key Laboratory for Geomechanics and Deep Underground Engineering, China University of Mining and Technology, Xuzhou, \\ Jiangsu 221116, China \\ ${ }^{3}$ Laboratory of Mine Cooling and Coal-Heat Integrated Exploitation, China University of Mining and Technology, Xuzhou, \\ Jiangsu 221116, China
}

Correspondence should be addressed to Guannan Liu; guannanliu@cumt.edu.cn

Received 6 December 2020; Revised 16 March 2021; Accepted 29 March 2021; Published 7 April 2021

Academic Editor: Guanglei Zhang

Copyright (C) 2021 Yuhao Hu et al. This is an open access article distributed under the Creative Commons Attribution License, which permits unrestricted use, distribution, and reproduction in any medium, provided the original work is properly cited.

\begin{abstract}
The rational characterization and quantitative analysis of the complex internal pore structure of rock is the foundation to solve many underground engineering problems. In this paper, CT imaging technology is used to directly characterize the threedimensional pore network topology of sandstone with different porosity. Then, in view of the problem, which is difficult to quantify the detailed topological structure of the sandstone pore networks in the previous study, the new complex network theory is used to characterize the pore structure. PageRank algorithm is based on the number of connections between targets as a measure index to rank the targets, so the network degree distribution, average path length, clustering coefficient, and robustness based on PageRank algorithm and permeability-related topological parameters are studied. The research shows that the degree distribution of sandstone pore network satisfies power law distribution, and it can be characterized by scale-free network model. The permeability of rock is inversely proportional to the average path length of sandstone network. The sandstone pore network has strong robustness to random disturbance, while a small number of pores with special topological properties play a key role in the macroscopic permeability of sandstone. This study attempts to provide a new perspective of quantifying the microstructure of the pore network of sandstone and revealing the microscopic structure mechanism of macroscopic permeability of pore rocks.
\end{abstract}

\section{Introduction}

Reservoir rocks contain huge numbers of pores with different sizes and complex shapes, and most part of the pores are connected with each other under the natural or artificial intervention, which is the main space for the migration of underground oil and gas. The connectivity of rock pore network directly affects the fluid flow behavior in geotechnical engineering [1-3]. However, the pore network of rock is highly complex. Accurately revealing the connectivity of micro and nanoscale and quantitatively analyzing the internal relationship between their microstructure and macroscopical permeability are the key problems to enhance the oil and gas recovery [4-7]. In order to study the microseepage mechanism of porous rock, scholars put forward the research methods based on continuum mechanics and pore network structure, respectively.

Based on the research method of continuum mechanics, Zhang et al. [8] coupled the gas flow control equation, coal deformation equation, and porosity model and established the permeability evolution model of multiporosity coal seam. Mitra et al. [9] studied the permeability variation of coal samples under the competitive mechanism of effective stress and adsorption expansion deformation. Pan et al. [10] studied the influence mechanism of effective stress on the permeability of coal samples, and the results show that the permeability of coal samples changed exponentially with gas pressure. Peng et al. [11] pointed out that under the same boundary 
conditions, there are significant differences in permeability of coal samples of different scales, and the sensitivity of permeability to confining pressure is also different. Pan [12] measured the permeability of coal samples in parallel, oblique, and vertical bedding directions. Lin and Zhou [13] found that the permeability of coal samples with parallel bedding is most closely related to the confining pressure effect and then studied the variation law of coal seam permeability with stress evolution under the action of in situ stress. Cao et al. [14] found by measuring the permeability of outburst raw coal that the permeability of coal seam first decreased and then increased with the gas pressure. Gao et al. [15] used the hybrid network theory to analyze the network parameters, modularization, and pore aggregation degree of sandstone with different porosity. This method can quantitatively analyze the structural parameters that cannot be quantified by traditional connectivity analysis and fractal dimension analysis. Ye et al. [16] established a dual pore network model of rock and analyzed the variation trend of permeability of coating model with microscopic parameters such as porosity distribution, average path length, and throat length distribution. Gong et al. [17] proposed a fractal reconstruction model of rock pore structure based on improved simulated annealing algorithm. The influences of pore radius and average pore shape factor on the pore structure characteristics of sandstone were analyzed from eight pore structure parameters, including pore number per unit volume, porosity, average pore size, pore volume, minimum maximum pore radius, and minimum average pore radius.

In order to analyze the influence mechanism of micropore structure on the permeability of porous rocks, Darabi et al. [18] studied the gas seepage process in dense porous media. Assuming that the porous media is composed of nano to millimeter pores, considering the influence of capillary roughness, the apparent permeability model was obtained. Singh et al. [19] obtained a new apparent permeability model by using analytical method without considering slippage effect. There are no empirical parameters in the model, which are only related to pore size, pore shape, temperature, gas properties, and average reservoir pressure. Yu et al. [20] proposed the fractal analysis model of porous media permeability and proposed the analytical expressions of fractal dimension, porosity, and microstructure of single-phase and multiphase porous media for the first time. Miao et al. $[21,22]$ extended the theory of fractal porous media to fracture network and constructed the fractal model of fracture network area density, which relates the structural parameters of fracture network, such as fracture size, fractal dimension, and porosity. Liu et al. [23] discussed the influence of size effect on permeability by combining seepage mechanics research method and Monte Carlo method to characterize fracture distribution mechanism. Li et al. [24, 25] developed a fully coupled multidomain multiphysics model to simulate the interactions between the fractured, nonfractured, and hydraulic fracture domains, taking into account the differences in properties and interactions between the fractured, nonfractured, and hydraulic fracture domains. Liu et al. [26-28] characterized pores and fractures by fractal dimension of pore, fractal dimension of curved capillary, and fractal
TABle 1: Comparison of continuous method and pore network method.

\begin{tabular}{lcc}
\hline $\begin{array}{l}\text { Characterization } \\
\text { methods }\end{array}$ & $\begin{array}{c}\text { Continuum } \\
\text { methods }\end{array}$ & $\begin{array}{c}\text { Pore network } \\
\text { methods }\end{array}$ \\
\hline Same parameters & Porosity & $\begin{array}{c}\text { Porosity } \\
\text { Number of pores } \\
\text { Average pore } \\
\text { diameter }\end{array}$ \\
Different parameters & $/$ & $\begin{array}{c}\text { Number of throat } \\
\text { Coordination } \\
\text { number } \\
\text { Clustering } \\
\text { coefficient }\end{array}$ \\
\hline
\end{tabular}

dimension of fracture length. Coupled the fractal theory of porous media with the multifield model of coal seam, they established a multifield coupling mechanical model considering the influence of fissure and pore structure. Li et al. [29] used Frenkel-Halsey-Hill method to obtain the fractal dimension of pores used to characterize the pores and obtained the structural parameters used to characterize the natural organic matter such as aliphatic chain length, aromatic carbon condensation degree, and hydrocarbon generation potential by peak fitting of infrared spectra. Considering the geometric parameters of porous media, including porosity, liquid saturation, fractal dimension of granular matrix and liquid phase, and fractal dimension of bending of liquid phase, Qin et al. [30] proposed a theoretical model of effective thermal conductivity of porous media with rough surface. Li et al. [31] discussed the influence of pore characteristic parameters such as fractal dimension of curvature, fractal dimension of pore, and minimum to maximum capillary diameter ratio on relative permeability. A detailed comparison is made between the continuous method and the pore material prevention method as shown in Table 1.

Firstly, based on continuum mechanics, the influence of micropore structure is generally not considered. Secondly, traditional reservoir structure analysis methods, such as Euler number and fractal dimension, are difficult to characterize the detailed topological properties of the pore network characteristics comprehensively and quantitatively. In order to solve the problem of scientific and quantitative characterization of microconnectivity characteristics of porous rock pores from the perspective of complex network theory, the topological structure and robustness characteristics of sandstone pore network were studied after obtaining CT images of sandstone with different porosity.

\section{Extraction of Core Pore Network}

Based on X-ray micron CT, four groups of two-dimensional tomography images of sandstone with different porosity are obtained, as shown in Figure 1. The experimental data comes from Professor Blunt's team of Imperial University of Technology. The data is public. The rock and equipment used in the experiment and the acquisition method of experimental data can be found on the official website of the team. See Acknowledgments for the website. The image shown in 


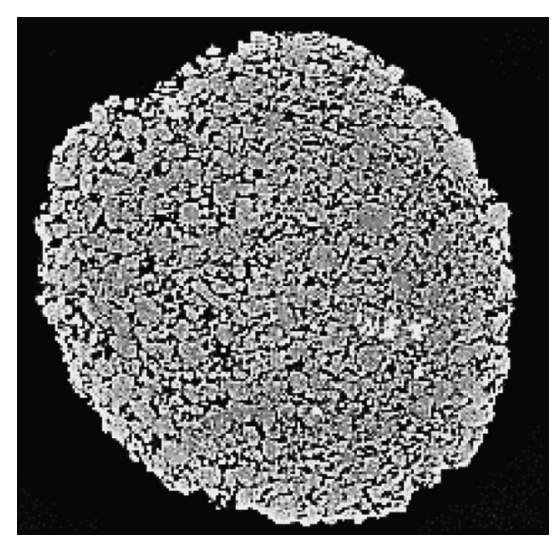

(a) $16.9 \%$ (voxel: $875 \times 900 \times 400)$

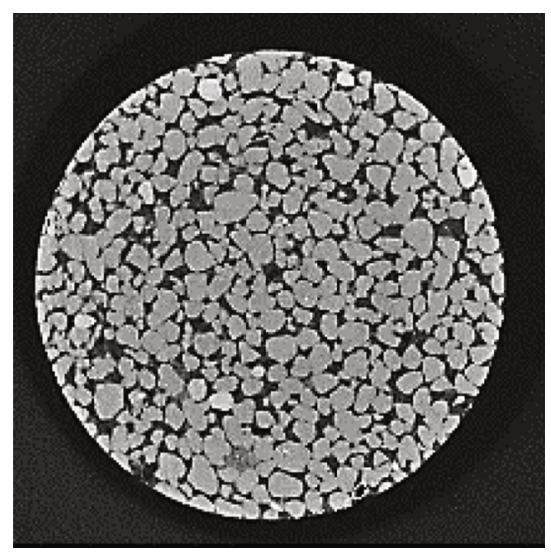

(c) $24.6 \%($ voxel: $950 \times 950 \times 300)$

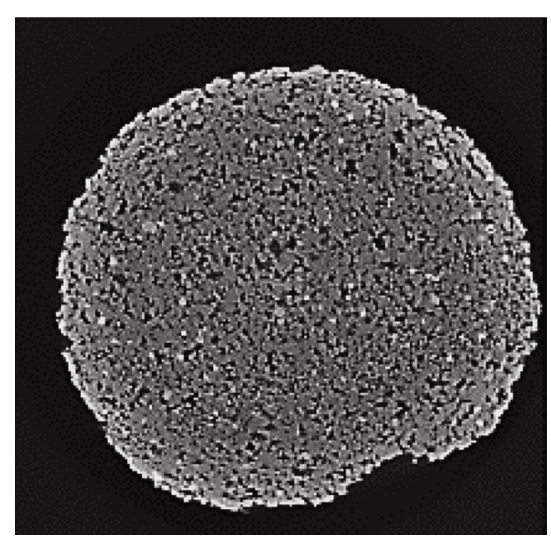

(b) $17.1 \%$ (voxel: $550 \times 550 \times 512)$

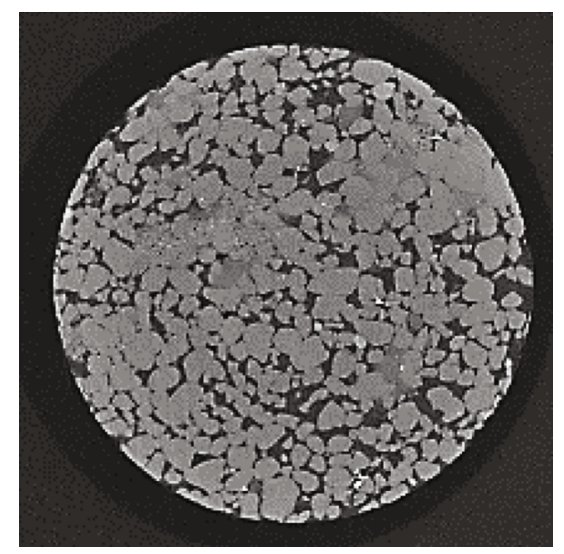

(d) $34.0 \%($ voxel: $950 \times 950 \times 350)$

FIGURE 1: X-ray tomography images of sandstone with different porosity.

Figure 1 is one of the slices of each sample. The gray level of each pixel in a two-dimensional image indicates the point density value. Considering that the area outside the rock sample is assigned black, it is eliminated for the analysis process, and the rectangular area is selected as the research object in the sample.

\section{Topological Structure Analysis of Pore Network Model}

In the research process of pore network structure, we use the network analysis software GEPHI, which has the function of searching and eliminating dead pores. Generally, pores with a diameter of less than $10 \mathrm{~nm}$ are micropores, pores with a diameter of $10 \mathrm{~nm}-100 \mathrm{~nm}$ are small pores, macropores with a diameter of $1000 \mathrm{~nm}-100000 \mathrm{~nm}$, and cracks with a diameter of over $100000 \mathrm{~nm} \mathrm{[32].} \mathrm{The} \mathrm{basic} \mathrm{parameters} \mathrm{of} \mathrm{sand-}$ stone samples with different porosity are shown in Table 1. From Table 2, it can be seen that when the porosity is small, such as $16.9 \%$ and $17.1 \%$, the number and of nodes in the pore network model are large. When the porosity is large, such as $24.6 \%$ and $34 \%$, the number of nodes in the pore network model is small, and it is less than $1 / 4$ of that of the rock sample of which porosity is $16.9 \%$. The main reason is that the smaller the porosity is, the smaller the particle size of the sandstone is, the smaller the volume of pore and pore throat is, so that the number of nodes in the network is more. The results show that the porosity is inversely proportional to the size of the pore network (the number of nodes).

Euler number and fractal dimension are usually used in the analysis of pore structure, and the topological structure of the pore network is difficult to be quantitatively analyzed. In this paper, the complex network theory analysis method is introduced into the pore network structure analysis, and the parameters such as the degree distribution, the clustering coefficient, and the average path length are calculated, respectively. The number of pore throat attached to a certain pore is defined as degree, which is usually expressed by $k$. In order to analyze the degree distribution of sandstone pore network, we counted the proportion of pores with different degrees to the total number of nodes expressed with $P(k)$, as shown in Figure 2. From Figure 2, it is known that the degree distribution curves of sandstone samples with different porosity have obvious long-tail characteristics. Different from the normal distribution, where most of the data are concentrated near the median, the distribution of sandstone pore network is more consistent with the scale-free network model which obeys the power law distribution.

The degree distribution is mainly used to measure the connected characteristics of the single pore in the sandstone pore network. In order to further explore the degree of aggregation between pores, the clustering coefficient is calculated. 
TABLE 2: Structural parameters of sandstone pore network.

\begin{tabular}{lcccc}
\hline $\begin{array}{l}\text { Porosity } \\
\varphi\end{array}$ & $\begin{array}{c}\text { Node number } \\
N\end{array}$ & $\begin{array}{c}\text { Edge number } \\
M\end{array}$ & $\begin{array}{c}\text { Permeability } \\
K(\mathrm{mD})\end{array}$ & $\begin{array}{c}\text { Resolution } \\
R(\mu \mathrm{m})\end{array}$ \\
\hline $16.9 \%$ & 8301 & 14381 & 224 & 9.1 \\
$17.1 \%$ & 8345 & 12360 & 259 & 9.0 \\
$24.6 \%$ & 1945 & 4697 & 3898 & 5.0 \\
$34.0 \%$ & 1266 & 3833 & 13169 & 4.9 \\
\hline
\end{tabular}

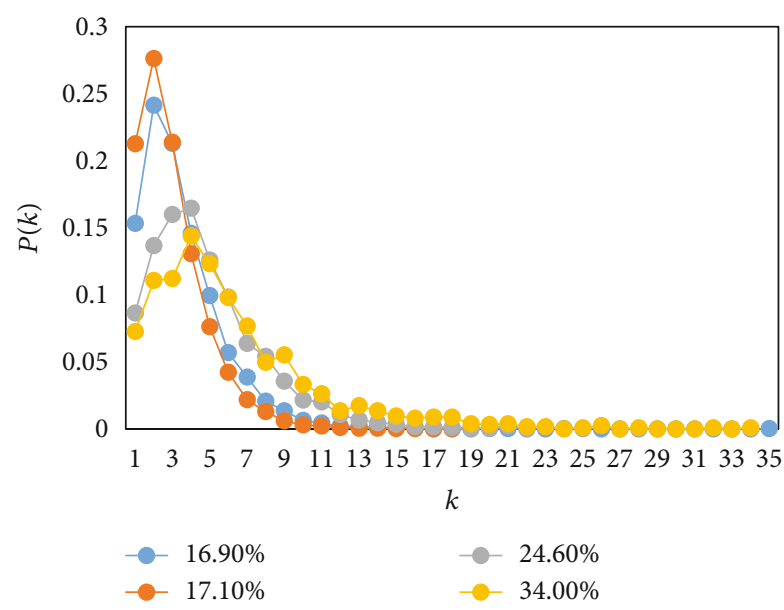

FIgURE 2: Degree distribution of sandstone pore networks.

Assumed that pore $i$ in a pore network has $k_{i}$ pores connected to it. The $k_{i}$ pores are called the neighbor pores of pore $i$. There is a maximum of $k_{i}\left(k_{i}-1\right) / 2$ throats among the neighbor pores of pore $i$. The ratio between the number of the actual throat number $N_{i}$ among pore $i$ 's neighbor pores and the number of the most probable throat number $k_{i}\left(k_{i}-1\right) /$ 2 is defined as the clustering coefficient of pore $i$, which is expressed as $C_{i}$.

$$
C_{i}=\frac{2 N_{i}}{k_{i}\left(k_{i}-1\right)}
$$

The value of $C_{i}$ changes between 0 and 1 in the network. The larger the $C_{i}$ is, the more the throats among pore $i$ and its neighbor pores are. The distribution of the pore network clustering coefficient of sandstone with different porosity is shown in Figure 3. The horizontal axis is the number of the pore node. As shown in Figure 3, the clustering coefficients of most of the pores are less than 0.6. Only a small number of pores are closely connected to the pores of the surrounding pores. These small amounts of pores may play an important role in the permeability of sandstone.

In order to measure the transmission efficiency of the network, the complex network theory gives a metric parameter "the average path length." The average path length $L$ of the sandstone network is the average number of throats between each pair of pores in the network.

$$
L=\frac{2}{N(N-1)} \sum_{i=1}^{N-1} \sum_{j=i+1}^{N} d_{i j}
$$

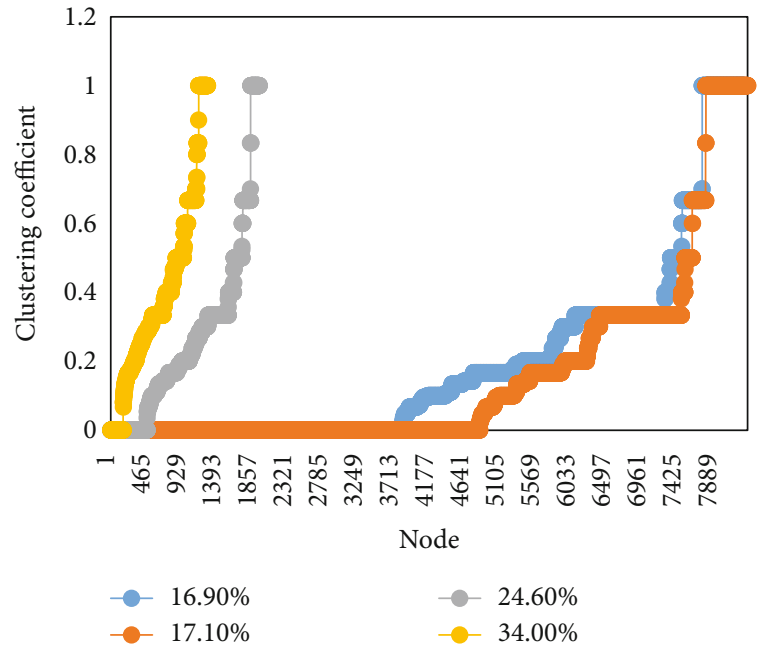

Figure 3: Distribution of clustering coefficient of sandstone pore network.

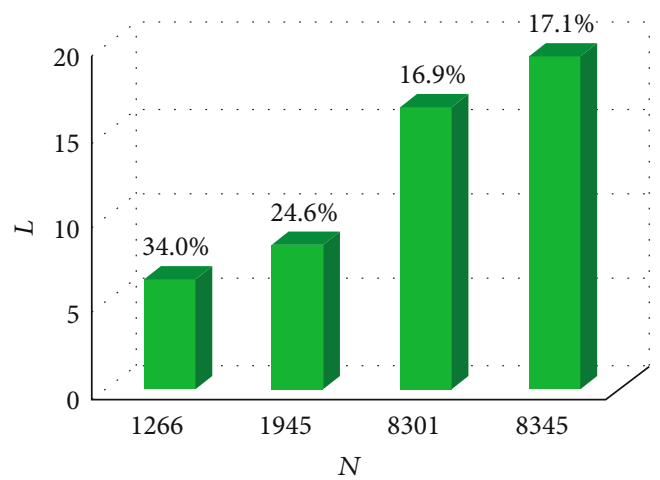

FIgURE 4: Distribution of average path length of sandstone pore network.

where $N$ is the number of pores in the network. $d_{i j}$ is the minimum number of throats between any two nodes of the network $i$ and $j$.

The average path length distribution of pore network in sandstone samples with different porosity is shown in Figure 4. From Figure 4, it is known that the average path length of the sandstone pore network is proportional to the number of pores, and it is inversely proportional to the porosity. And the greater the porosity, the larger the permeability of sandstone and the smaller the average path length would be.

\section{Analysis of the Robustness of Pore Network}

Usually, we do not consider the importance of a single pore in the whole percolation network when analyzing the pore structure. In order to investigate whether a single or a small number of pores will lead to significant changes in the transmission efficiency of the whole seepage network, that is, whether the permeability of the rock network depends on a small number of important pores, we 


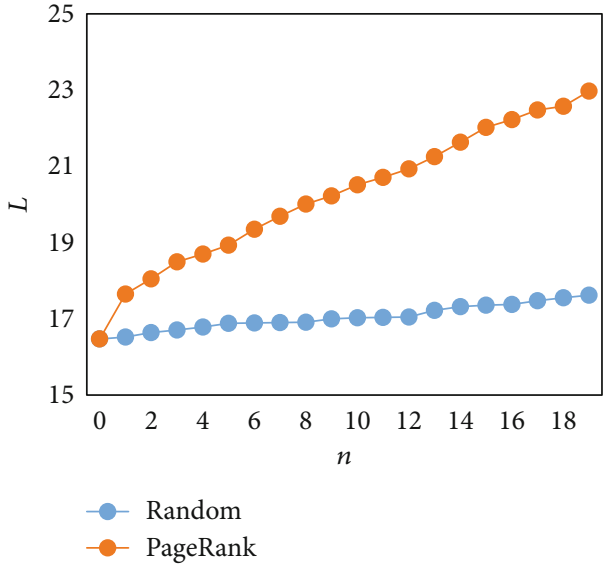

(a) $16.9 \%$

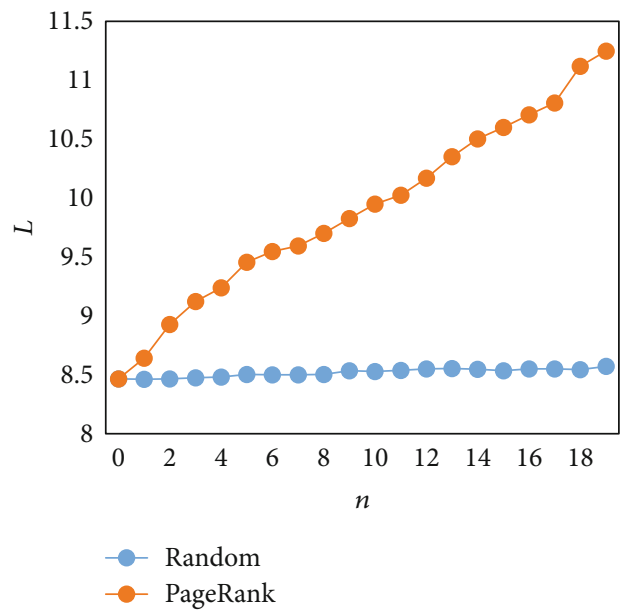

(c) $24.6 \%$

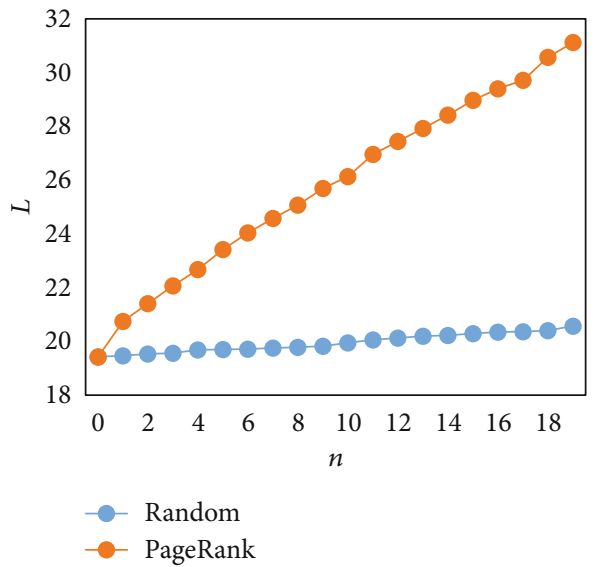

(b) $17.1 \%$

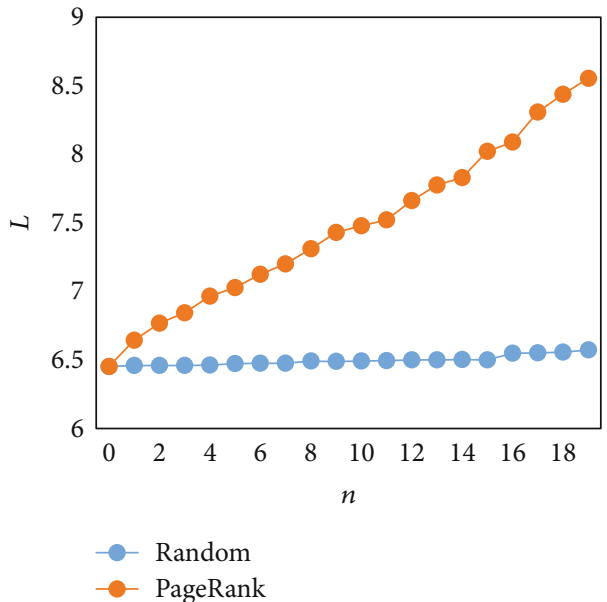

(d) $34.0 \%$

FIgURE 5: The robustness curve of sandstone with different porosity.

have studied the robustness of the sandstone pore network.

In the network science, the average path length is the key parameter to measure the transmission efficiency of the network. The smaller the average path length is, the higher the network transmission efficiency is. We eliminate the pore nodes in the pore network based on two methods and then discuss the evolution process of network transmission efficiency. Method 1: random elimination; method 2: elimination based on PageRank algorithm.

As the sorting algorithm in the complex network theory, the PageRank algorithm is based on the network topology as the importance of the network node importance. The basic idea of the PageRank algorithm is that the pore network is regarded as graph $G=(V, E)$, where $V$ is the number of notes and $E$ is the number of edges. Give each node an initial PageRank value. Suppose there is an edge $\left(v_{i}, v_{j}\right)$ between node $v_{i}$ and node $v_{j}$, then node $v_{i}$ throws a ticket to the node $v_{j}$. Using $C^{\prime}(i)$ to represent the number of edges connected with node $i$, then node $v_{i}$ contributes a PageRank value of $P^{\prime}(i) / C^{\prime}(i)$ to the node $v_{j}$. The algorithm process is as follows.

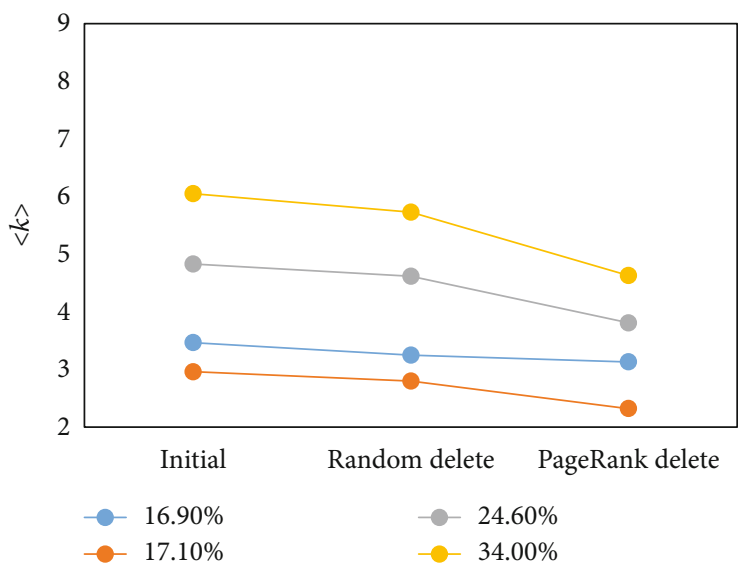

FIgURE 6: Average degree change curve under different elimination schemes.

First, define the initial PageRank value for each node $v_{i}$ :

$$
P_{0}^{\prime}(i)=\frac{1}{(n+1)}, 0<i \leq n
$$




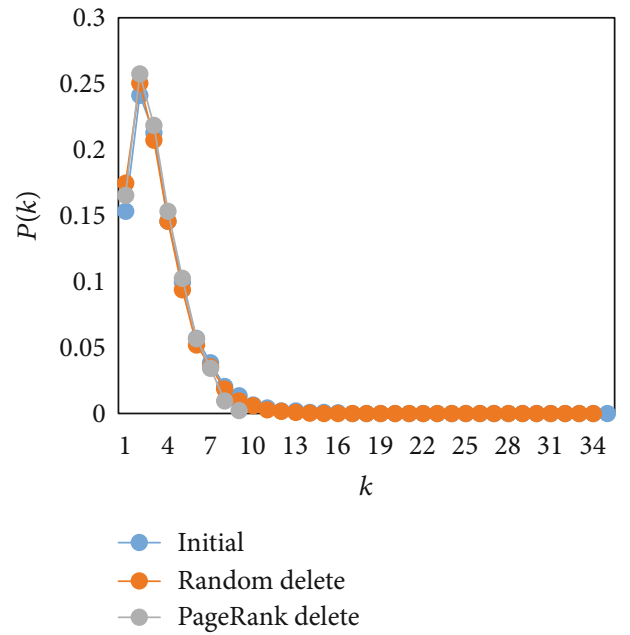

(a) $16.9 \%$

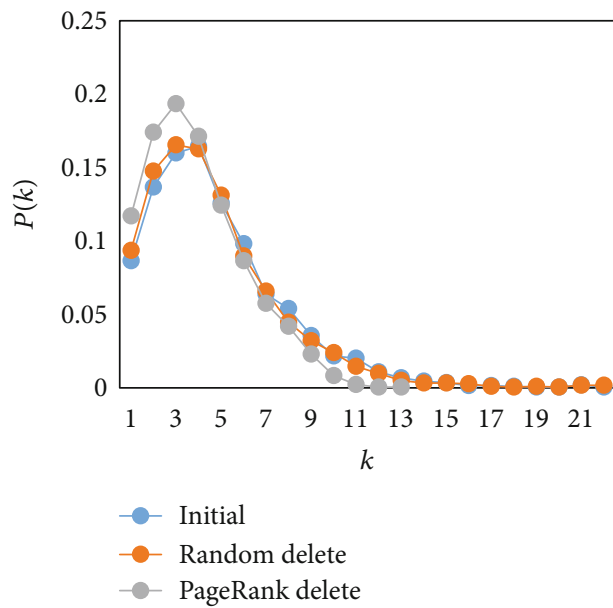

(c) $24.6 \%$

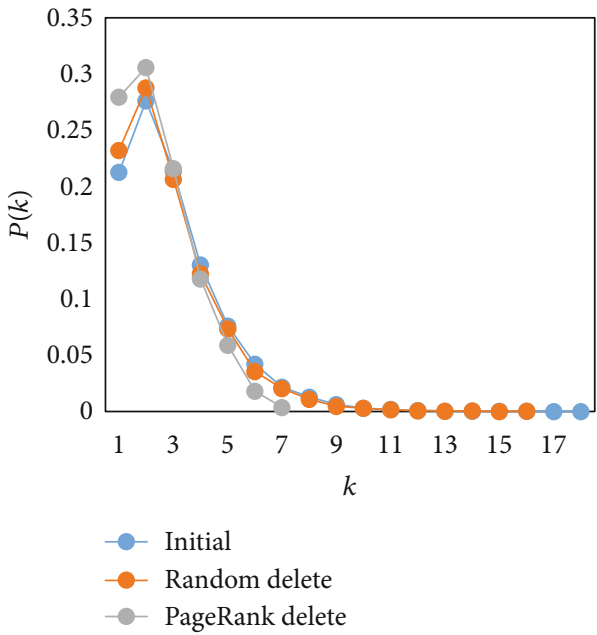

(b) $17.1 \%$

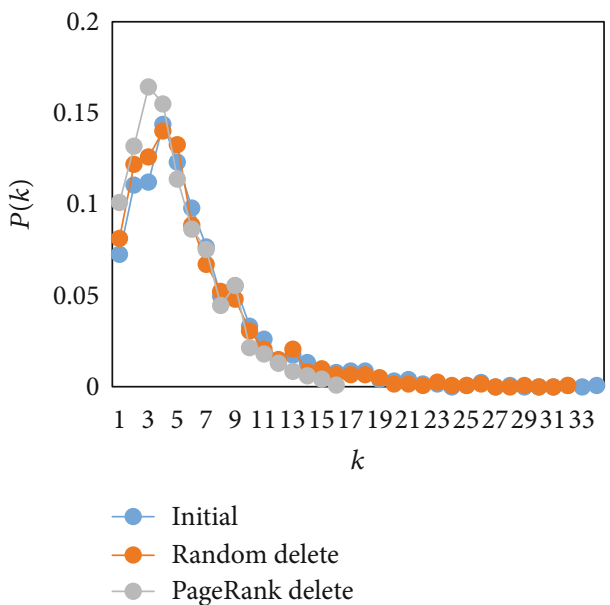

(d) $34 \%$

Figure 7: Pore network degree distribution of sandstone under different deletion schemes.

After the $s$ times of iteration, the PageRank value of each node is as follows:

$$
P_{s}^{\prime}(i)=(1-d)+d \times \sum_{\left(V_{j}, V_{i}\right) \in E} \frac{P_{s-1}^{\prime}(j)}{C^{\prime}(j)}, 0<i \leq n
$$

where $d$ is a damping factor $(0<d<1)$, which represents the probability of connecting a node. In this iterative way, multiple rounds are iterated until the PageRank value converges or when the sum of the PageRank value changes of all nodes is less than the custom threshold. Then, the pores are sorted according to the PageRank values.

The evolution process of the average path length is calculated as shown in Figure 5 according to two schemes, which are random deletion and PageRank-sorted deletion from the most important node. The horizontal coordinate axis is the number of deleting nodes, and the total amount of removing pores is $5 \%$ of the total number of pores. It can be seen from Figure 5 that when the pores in the sandstone pore network are randomly deleted, the average path length of the sandstone pore network increases only slightly. When the PageRank algorithm was used to rank the importance of pores and remove important nodes, the average path length increased significantly. It can be concluded that in the sandstone pore network, a small number of important nodes selected by the PageRank algorithm play a crucial role in the permeability of the whole macroscopic network. In the process of underground oil and gas exploitation, under the action of ground stress, adsorption, and desorption, if these key pores are plugged, it may cause significant change in the whole network permeability [19-22].

The variation curve of the average degree of pore network of sandstone under the two node elimination schemes is shown in Figure 6. As shown in Figure 6, compared with random deleting nodes, the decrease of pore average degree in the node deletion scheme based on PageRank algorithm is more obvious. That is, the overall connectivity of the sandstone pore network has been obviously weakened. In order to analyze the specific evolution process of the network degree distribution, we calculated the contrast curves before and after the deletion of the pores, as shown in Figure 7. 


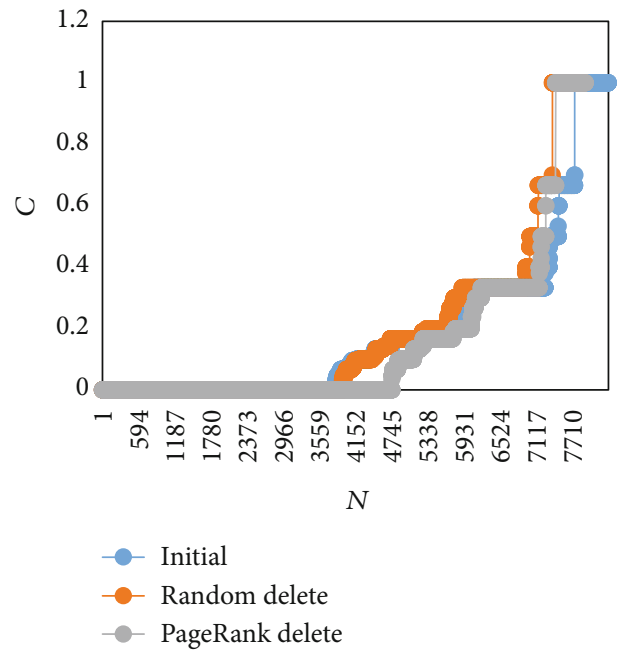

(a) $16.9 \%$

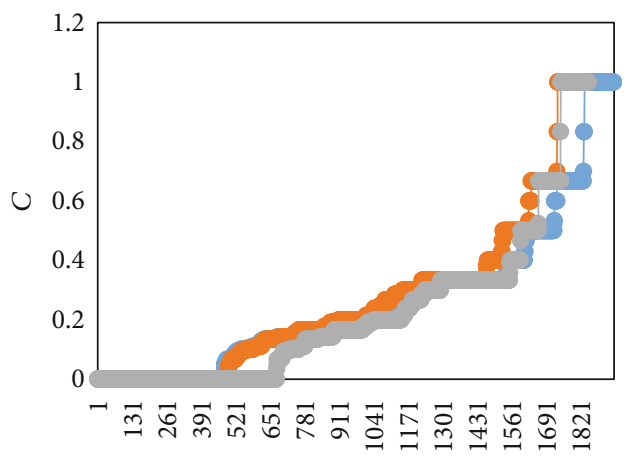

$N$

$$
\begin{aligned}
& \text { - Initial } \\
& \text {-- Random delete } \\
& \text {-- PageRank delete }
\end{aligned}
$$

(c) $24.6 \%$

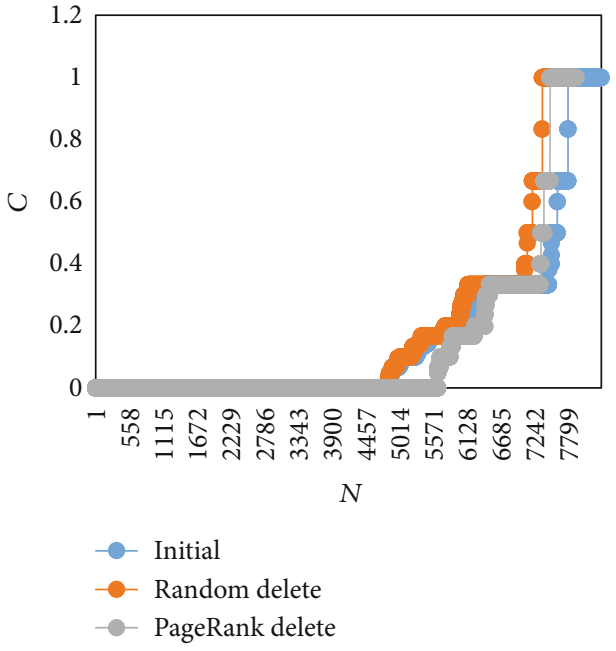

(b) $17.1 \%$

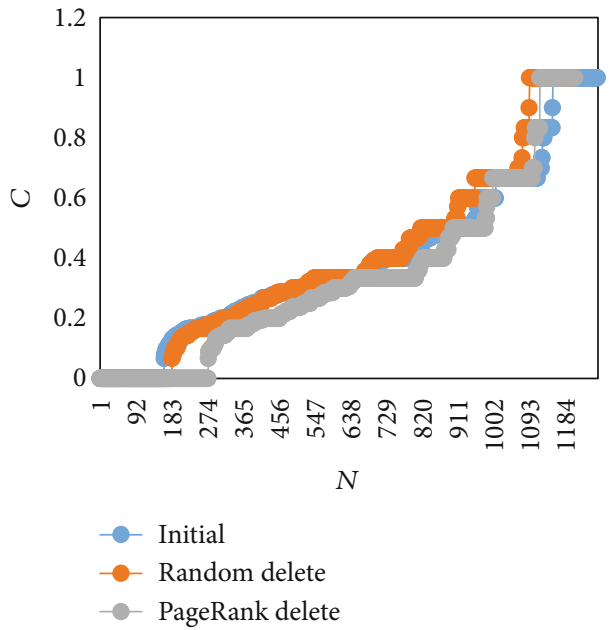

(d) $34.0 \%$

Figure 8: Clustering coefficients of sandstone pore network under different elimination schemes.

From Figure 7, it is known that random deleting nodes have little influence on the overall pore network degree distribution, and the curves before and after deletion are basically coincided. And before and after the node deletion based on the PageRank algorithm, the data of the back section of the curve are significantly reduced. The main reason is that the PageRank algorithm sorted the more important nodes, whose degree is larger, that is, the connectivity is stronger. Therefore, most of the nodes which have been deleted by the second scheme are the nodes with the large degree. This is also the reason for the obvious decrease in the average degree of the deletion method based on PageRank scheme in Figure 6.

The clustering coefficient is the coefficient that indicates the degree of node aggregation. This property is the clustering characteristic of the network. According to Figure 8, the distribution of the clustering coefficient of sandstone pore network has little change under different deletion schemes. In order to analyze the overall aggregation degree of sandstone pore network, we calculated the average clustering coefficient of pore network of different porosity sandstone, as shown in Figure 9.

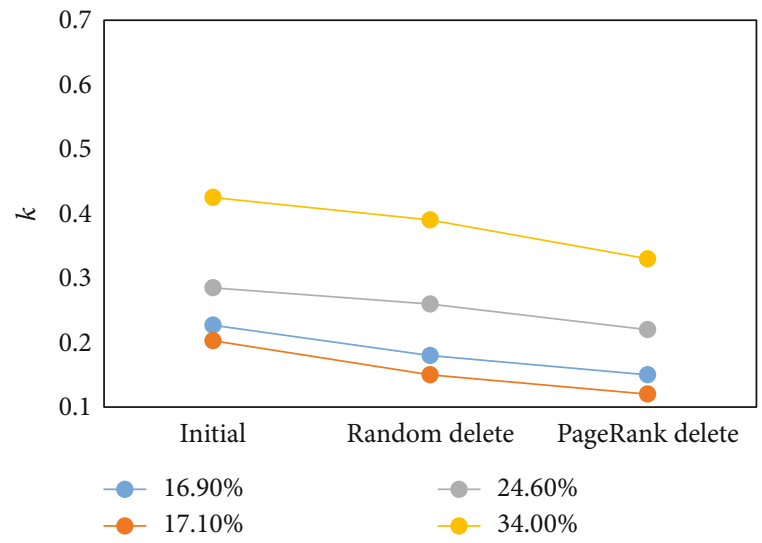

Figure 9: Comparison of the average clustering coefficient of sandstone pore network under different elimination schemes.

Compared with Figures 8 and 9, we can see that although the distribution of clustering coefficients changes slightly before and after the deletion, the average clustering coefficient 


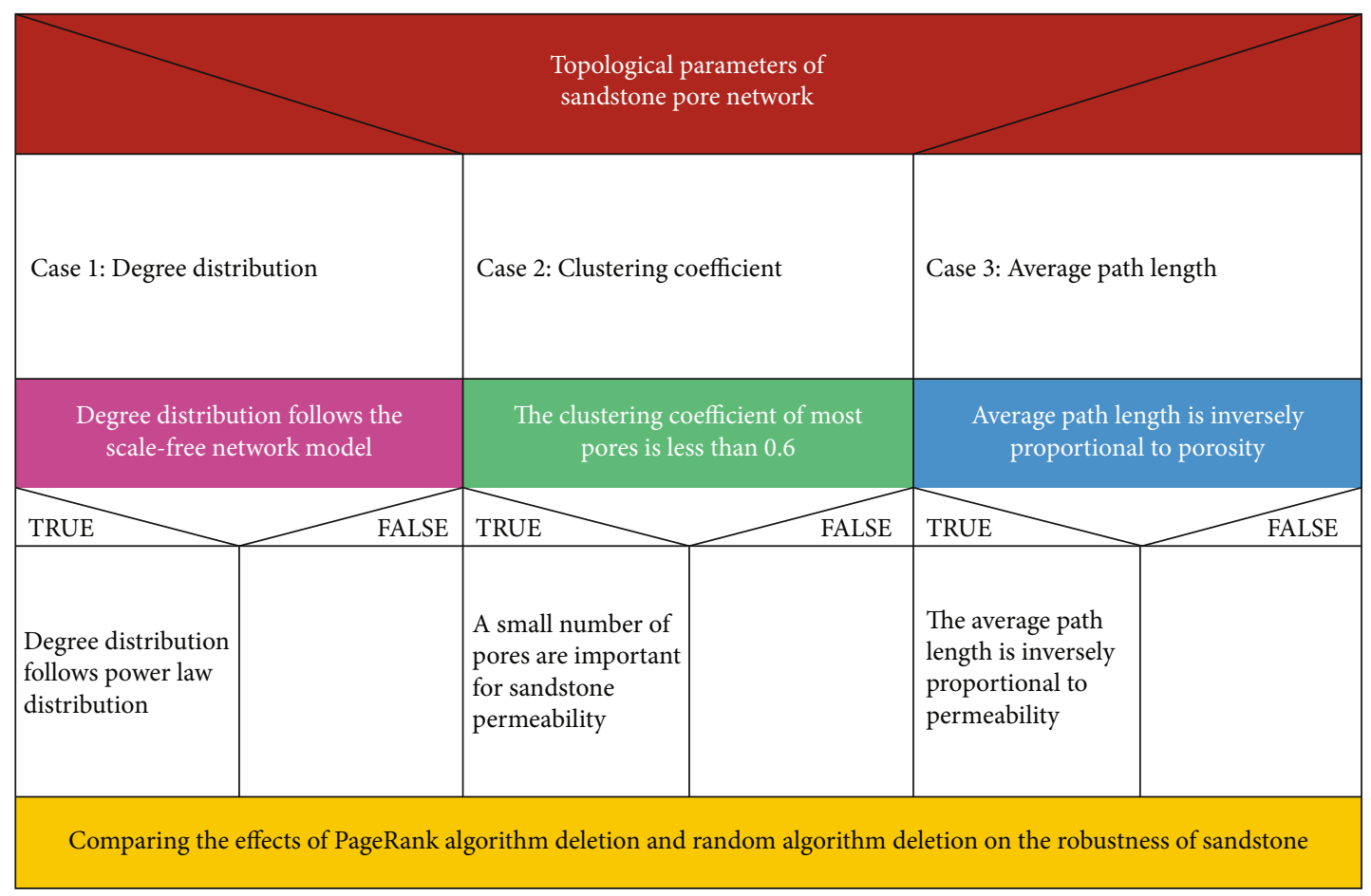

FIGURE 10: N-S diagram of the overall process of pore network analysis.

of the network has been significantly reduced. Especially the deletion method based on the PageRank algorithm, the clustering coefficients of the four porosity sandstone networks have decreased by about 0.1 . The main reason is that the PageRank algorithm elimination scheme deletes a large number of nodes with large degree. That is, a large number of edges (throats) have been deleted, which leads to a significant reduction in the overall connectivity of the network. The pore network analysis process is shown in Figure 10.

\section{Conclusions and Discussion}

In this work, the complex network theory is used to study the characteristics of rock network. The degree distribution, clustering coefficient distribution, and average path length of the three-dimensional pore network are discussed, and the robustness of the network is also analyzed. The conclusions are as follows:

(1) Compared with the random model, the porosity distribution is more consistent with the scale-free network model of power-law distribution, that is, the porosity network of sandstone has no obvious characteristic value

(2) The average path length of sandstone pore network is directly related to the network size. The larger the aperture volume, the smaller the number of network nodes and the smaller the average path length. PageRank is a function defined in the pore network structure. It gives a positive real number for each pore, which indicates the importance of the pore and forms a vector as a whole. The higher the PageRank value is, the more important the pore is. Compared with the random model scheme, the average path length of the PageRank deletion scheme is much more significant than that of the random model scheme when the same few nodes are deleted by the PageRank algorithm, which may have a greater impact on the permeability of the whole sandstone pore network $[20,21]$

(3) The pore network of sandstone is robust to random deletion. However, a few special nodes selected by the PageRank algorithm are deleted, which greatly reduces the transmission performance of the network. By comparing the stochastic model with the PageRank algorithm model, it is shown that the special pore structure plays a key role in the connectivity of the whole network. Based on the influence of the robustness of sandstone pore network on permeability, it can be used to select the position with strong robustness as the production well location in engineering, so as to ensure the stability of permeability and gas production.

\section{Data Availability}

Data used to support the results from the experimental results can be obtained at the university of British imperial, and access to sites is as follows: https://www.imperial.ac.uk/ earth-science/research/research-groups/perm/research/ pore-scale-modelling/micro-ct-images-and-networks/. 


\section{Conflicts of Interest}

The authors declare that they have no conflicts of interest.

\section{Acknowledgments}

This research was funded by the open fund of Jiangsu Key Laboratory of Coal-based Greenhouse Gas Control and Utilization (Grant No. 2017B06). The data and methods for this study are from the website of Imperial College London, UK, which is linked below: https://www.imperialL.ac.uk/earthscience/research/research-groups/perm/research/pore-scalemodelling/micro-ct-images-and-networks/.

\section{References}

[1] J. Zeng, J. Liu, W. Li, Y. K. Leong, D. Elsworth, and J. Guo, "Evolution of shale permeability under the influence of gas diffusion from the fracture wall into the matrix," Energy \& Fuels, vol. 34, no. 4, pp. 4393-4406, 2020.

[2] J. Zeng, X. Wang, J. Guo, F. Zeng, and F. Zeng, "Modeling of heterogeneous reservoirs with damaged hydraulic fractures," Journal of Hydrology, vol. 574, pp. 774-793, 2019.

[3] Y. Xue, T. Teng, F. Dang, Z. Ma, S. Wang, and H. Xue, "Productivity analysis of fractured wells in reservoir of hydrogen and carbon based on dual-porosity medium model," International Journal of Hydrogen Energy, vol. 45, no. 39, pp. 20240-20249, 2020.

[4] J. Liu, X. Liang, Y. Xue, K. Yao, and Y. Fu, "Numerical evaluation on multiphase flow and heat transfer during thermal stimulation enhanced shale gas recovery," Applied Thermal Engineering, vol. 178, p. 115554, 2020.

[5] H. Wang, R. Shi, D. Deng, Y. Jiang, G. Wang, and W. Gong, "Characteristic of stress evolution on fault surface and coal bursts mechanism during the extraction of longwall face in Yima mining area, China," Journal of Structural Geology., vol. 136, p. 104071, 2020.

[6] H. Wang, S. Xue, R. Shi, Y. Jiang, W. Gong, and L. Mao, "Investigation of fault displacement evolution during extraction in longwall panel in an underground coal mine," Rock Mechanics and Rock Engineering, vol. 53, no. 4, pp. 18091826, 2020.

[7] C. Wang, J. Zhang, Y. Zang et al., "Time-dependent coal permeability: impact of gas transport from coal cleats to matrices," Journal of Natural Gas Science and Engineering, vol. 88, p. 103806, 2021.

[8] S. Zhang, J. Liu, M. Wei, and D. Elsworth, "Coal permeability maps under the influence of multiple coupled processes," International Journal of Coal Geology, vol. 187, pp. 71-82, 2018.

[9] A. Mitra, S. Harpalani, and S. Liu, "Laboratory measurement and modeling of coal permeability with continued methane production: part 1-laboratory results," Fuel, vol. 94, pp. 110116, 2012.

[10] Z. Pan, L. D. Connell, and M. Camilleri, "Laboratory characterisation of coal reservoir permeability for primary and enhanced coalbed methane recovery," International Journal of Coal Geology, vol. 82, no. 3-4, pp. 252-261, 2010.

[11] Y. Peng, Q. Qi, Z. Deng, and H. Li, "Experimental study on permeability sensitivity of coal sample to confining pressure considering scale effect," Journal of China Coal Society, vol. 33, no. 5, pp. 509-513, 2008.

[12] R. Pan, Permeability Evolution Characteristics of Loaded Coal Body and Its Application in Relief Gas Drainage, China University of Mining and Technology, 2014.

[13] B. Lin and S. Zhou, "Experimental study on gas permeability of coal sample," Journal of China Institute of Mining and Technology, vol. 1, pp. 24-31, 1987.

[14] S. Cao, P. Guo, Y. Li et al., "Effect of gas pressure on permeability characteristics of raw coal," Journal of China Coal Society, vol. 35, no. 4, pp. 595-599, 2010.

[15] F. Gao, Y. Hu, G. Liu, and Y. Yang, "Experiment study on topological characteristics of sandstone coating by micro CT," Coatings, vol. 10, no. 12, p. 1143, 2020.

[16] D. Ye, G. Liu, F. Gao, X. Zhu, and Y. Hu, "A study on the structure of rock engineering coatings based on complex network theory," Coatings, vol. 10, no. 12, p. 1152, 2020.

[17] L. Gong, L. Nie, and Y. Xu, "Geometrical and topological analysis of pore space in sandstones based on X-ray computed tomography," Energies, vol. 13, no. 15, p. 3774, 2020.

[18] H. Darabi, A. Ettehad, F. Javadpour, and K. Sepehrnoori, "Gas flow in ultra-tight shale strata," World Journal of Engineering, vol. 6, no. 3, pp. 7-15, 2009.

[19] H. Singh, F. Javadpour, A. Ettehadtavakkol, and H. Darabi, "Nonempirical apparent permeability of shale," SPE Reservoir Evaluation \& Engineering, vol. 17, no. 3, pp. 414-424, 2014.

[20] B. Yu and P. Cheng, "A fractal permeability model for bidispersed porous media," International Journal of Heat and Mass Transfer, vol. 45, no. 14, pp. 2983-2993, 2002.

[21] T. Miao, B. Yu, Y. Duan, and Q. Fang, "A fractal analysis of permeability for fractured rocks," International Journal of Heat and Mass Transfer, vol. 81, pp. 75-80, 2015.

[22] T. Miao, S. Yang, Z. Long, and B. Yu, "Fractal analysis of permeability of dual-porosity media embedded with random fractures," International Journal of Heat and Mass Transfer, vol. 88, pp. 814-821, 2015.

[23] R. Liu, Y. Jiang, B. Li, S. Wang, and S. Xun, "Numerical calculation of directivity of equivalent permeability coefficient of rock fracture network," Rock and Soil Mechanics, vol. 35, no. 8, pp. 2394-2400, 2014.

[24] W. Li, Z. J. Liu, J. Zeng et al., "A fully coupled multidomain and multiphysics model for evaluation of shale gas extraction," Fuel, vol. 278, article 118214, 2020.

[25] W. Li, Z. J. Liu, and Y. Leong, "A fully coupled multidomain and multiphysics model for shale gas production," in Presented at the 5th ISRM Young Scholars' Symposium on Rock Mechanics and International Symposium on Rock Engineering for Innovative Future, 1-4 December, Okinawa, Japan, 2019https://www.onepetro.org/conference-paper/ISRMYSRM-2019-063.

[26] G. Liu, B. Yu, D. Ye, F. Gao, and J. Liu, "Study on evolution of fractal dimension for fractured coal seam under multi field coupling," Fractals, vol. 28, no. 4, article 2050072, 2020.

[27] G. Liu, J. Liu, L. Liu, D. Ye, and F. Gao, "A fractal approach to fully-couple coal deformation and gas flow," Fuel, vol. 240, pp. 219-236, 2019.

[28] G. Liu, D. Ye, F. Gao, and J. Liu, "A dual fractal poroelastic model for characterizing fluid flow in fractured coal masses," Geofluids, vol. 2020, Article ID 2787903, 13 pages, 2020.

[29] K. Li, S. Kong, P. Xia, and X. Wang, "Microstructural characterisation of organic matter pores in coal-measure shale," 
Advances in Geo-Energy Research, vol. 4, no. 4, pp. 372-391, 2020.

[30] X. Qin, Y. Zhou, and A. P. Sasmito, "An effective thermal conductivity model for fractal porous media with rough surfaces," Advances in Geo-Energy Research, vol. 3, no. 2, pp. 149-155, 2019.

[31] Z. Li, Y. Duan, Q. Fang, and M. Wei, “A study of relative permeability for transient two-phase flow in a low permeability fractal porous medium," Advances in Geo-Energy Research, vol. 2, no. 4, pp. 369-379, 2018.

[32] Q. Yu, Mine Gas Prevention, China University of Mining and Technology Press, 1992. 